\title{
Simulating Direct Democracy in the Classroom: A Minimal Group Experimental Design
}

\author{
Kristina Flores-Victor \\ California State University, Sacramento
}

\begin{abstract}
This paper describes a simulation used in American Government and California Politics and California Policy courses. The in-class simulation mimics the use of direct democracy in California over a single election season. Using knowledge from previous class periods students participate in a more active learning environment, to understand some of the impacts of legislating through propositions and how certain groups participate in the political process. The simulation uses a minimal group experimental set-up to allow the students to potentially participate as a member of different group in society. Persistent findings across simulations show lessons for coalition building, leadership, negotiation, resource allocation, campaign strategy, group identity and cohesion, trust among groups, and political apathy.
\end{abstract}

Key words: California Politics, Direct Democracy, Propositions, Simulations and Games, Minority Politics, American Government, Political Strategy in American Politics

This manuscript was prepared for presentation at the 2020 APSA Teaching and Learning Conference is Albuquerque, New Mexico. 


\section{Introduction:}

There are several interesting challenges when designing a course--how do I keep my students interested, how do I explain core concepts and theories with application to real life, and how do I encourage students to examine politics from diverse perspectives. Using a carefully designed simulation, played in class, I can begin to address all three of these challenges. In this paper I describe the use of a simulation I have designed around direct democracy in California. The purpose of the simulation is to have students apply their previous knowledge of direct democracy in a more active learning environment, to understand some of the impacts of legislating through propositions, and how certain groups participate in the political process.

\section{Simulations and Active Learning}

Carefully designed in-class simulations, connected to course content, can be a powerful pedagogical tool (Wedig 2010). Simulations help address different student learning styles and engage students in higher level learning. Simulations also generate additional interest in the course, and make concepts and theories more memorable and applicable to everyday political life (Silva 2012).

Addressing different learning styles and higher level learning. Brock and Cameron (1999) and Wedig (2010) explain students learn in different ways, a more traditional lecture style may work very well for certain students, but there are others who will not process or engage with the information as deeply or productively. By incorporating different teaching methods we are able to reach a greater variety of learners in our classrooms. Also, the problem solving skills required by simulations allow students to engage in higher order learning, as described by Bloom's Taxonomy (1956); when they apply theoretical concepts to analyze, synthesize, and evaluate political problems and solutions (Lantis et al 2010; Silva 2012). Students also have opportunities for public speaking and presentations in front of smaller audiences without being graded (Smith and Boyer 1996).

Generate interest in the course, especially for non-majors. Simulations can help students develop a deeper connection to the course and interest in the topics (Brock and Cameron 1999; Shellman and Turan 2006; Lantis et al 2010; Schnurr et al 2014). These potential impacts could be especially important when we think about retaining majors in our field or when we teach introductory courses or GE courses with non-majors. During simulations students are able to learn from one another and bring in diverse perspectives not taught by the instructor. The active learning experience brings theories and concepts to life as students are empowered to explore the boundaries of the simulation and collaborate with one another (Smith and Boyer 1996; Lantis et al 2010). Wedig (2010) explains that in competitive 
simulation environments students may strive to outplay other students to make sure their team wins or performs well relative to other teams.

Concepts and theories are more memorable. Shellman and Turan (2006) evaluate in-class IR simulations to show that students gain and retain increased knowledge of relevant theories and concepts. In Schnurr et al (2014) and Wedig (2010) they show role-play simulations challenge idealism or inexperience, leaving students with a more realistic view of the complex challenges faced when dealing with power differentials, negotiations, coalition building, and policy making. Smith and Boyer (1996) and Lantis et al (2010) explain a possible mechanism, simulations let students feel and internalize the limitations and motivations rather than just reading or hearing about them from the text or the instructor, through this students are able to better understand theories and concepts.

\section{Student Learning Objectives}

This simulation has been run in three different types of courses over the last five years; an American Government course, a California Public Policy course, and a California State and Local Politics course. The simulation has been run in courses containing all political science majors and also in GE courses with non-majors. The simulation addresses two of the main learning objectives for these three courses. The two learning objectives include: (1) explaining, analyzing, and evaluating the structure and function of California's constitution, particularly as related to direct democracy, and (2) the role of identity and social dynamics in campaigns and politics.

\section{The Election Simulation}

Materials for simulation:

1. $5 \times 5$ colored cards (blue, orange, purple, pink, yellow, green)

2. Three types of colored poker chips

a. $\operatorname{Red}=$ reward

b. Blue = political capital

c. White = income

3. Small bags (solid color bags)

4. Profile sheet for each team

5. Trivia questions (professor)

6. Timer (professor)

The format of this simulation is synchronous, in-class, and face-to-face. The simulation is played following lectures and assigned reading on direct democracy; in this particular case the courses where this simulation have been played are upper division courses on: (1) California State and Local Politics (2) American Governments, and (3) California Public Policy; first two courses are General Education 
requirements. This simulation does not require any additional preparation from the students and can be played as a one to two class period simulation depending on the length of the class period (2.5 hours is ideal). A full list and description of the materials is included above.

I use a minimal group experimental design for the simulation (Tajfel, 1970; Tajfel et al 1971; Tajfel 1978). The minimal group design allows for students to form an (temporary) identity apart from their real political or social identities; party identification is not part of the simulation. This allows students to participate and experience politics from a different perspective. At the start of class, students are randomly given a small 5x5 colored voting card and instructed that they are going to play a game. Typically students (on their own) will begin moving to sit by other students with the same color voting card. Once students have self-sorted to sit in their teams, I give them a small bag with the team materials and instruct them not to look inside. The class then plays a short trivia game (sports, entertainment, history, literature, pop culture). The trivia questions are asked by me, one team spokesperson is allowed to answer on behalf of the group, with no phones or computers. The groups receive a prize (white or blue poker chips) for correct answers. After the short trivia game (typically five questions) the simulation begins.

Students are instructed they are part of a population inhabiting a new planet and the new planet has adopted a system of direct democracy, a legislature, and an executive. The class is given general information about the composition of this new society, including each group's population distribution, poverty level, educational attainment, homeownership, political representation, and healthcare access. I explain the class will be simulating an election season, the elections use: first-past-the-post, plurality voting, and instant runoff in cases of a tie. Students are now allowed to look in their bags, and in the bags are two resources: (1) a group profile based on the color card they have and (2) an array of poker chips. The profiles for the groups are based off of real profiles for different types of voters in society. In the simulations I run I use the information for different racial and ethnic groups in California. Groups are given information concerning average: home ownership, educational attainment, employment/unemployment, percent incarcerated, age distribution, business ownership, income, percent in the population, access to resources, percent representation in the current legislature.

At this point in the simulation I also explain that the bag contains the groups' resources for the game, two different color poker chips (white and blue). Each group has different starting resources depending on the profile for their group. The chips they received for playing the trivia game are then added to the group bag. A second round of trivia is played with white and blue chips given as prizes. 
Typically by this time in the simulation (approximately 5-10 minutes in the game) the groups have formed very tight bonds and have already begun identifying with their group, as noted by their jeering and bragging during the second round of trivia.

Once the two rounds of trivia are played and the groups have read their profiles we begin the election season. I explains we will vote on propositions during the simulation and they will have time to debate, caucus, and strategize prior to voting on each proposition. The class debates, caucuses, and votes on the propositions one at a time, however a simple variation in the game is to let the students debate all the propositions at once and vote at the end, allowing for different types of bargaining, coalition formation and negotiation.

Before the first proposition is announced I explain the exchange rate for the poker chips. The white chips are income and they can be earned in the trivia game, groups have a set amount of starting income directly related to their average income in society. The blue chips represent political capital and are paid for and acquired using income chips, the exchange rate is two white stacks (10 chips) for one blue stack (5 chips). Thus, groups with higher starting income have more access to political capital. Certain groups receive blue chips in their bag of starting resources, and some groups receive no blue chips to begin the simulation.

Before debating and possibly voting on the first proposition I explain to the class that there are multiple methods to influence an election. One method is to use the resources in the game, the blue poker chips can be spent to disrupt the election by knocking candidates out of the race, or keeping propositions off the ballot. Additional political capital can then be spent ( $2 \mathrm{x}$ the amount) to reestablish a candidate in a race, or a proposition on the ballot. The less description of when and how the rules will work is best, this allows groups to more creatively discuss and strategize when they are caucusing.

The six propositions considered in the simulation in order of appearance are: education reform, access to healthcare, criminal justice, affordable housing, immigration reform, and regulation reform. The simulation also features an election for the executive (veto power/cooling off period) and an election for a legislature. As previously mentioned each proposition or election is considered on its own. For each proposition I provide an explanation of what will happen if the proposition is passed/not passed by the electorate. The explanation provided describes which groups will receive a reward (red chips), what groups may have a punishment or have to pay a portion of their income (white chips). No directions are given for caucusing, bargaining, leadership, secrecy, spending, or strategy. I give a set amount of time they are allowed to discuss and always allow the groups more time if they request. 
The order of the direct democracy propositions matter, I have purposefully designed certain propositions to cut through possible coalitions after they have formed. During the simulation there are built-in breaks where we play the trivia game and groups are able to earn some additional resources for the game. In this simulation the professor has the role of a facilitator and observer, not an active participant in the simulation.

\section{Student Experiences During the Simulation}

Students and groups are not provided any additional instruction on how to play the simulation, yet I observe persistent themes, outcomes, and behaviors over all types of classes participating in the simulation. My evaluation and assessment strategy is a group debriefing (Smith and Boyer 1996). I keep careful notes during the simulation that I use during our debriefing session. I allow the students time to vent about the simulation and describe all of their perceived or real grievances; within groups and across groups.1 I then pose open-ended questions to the class during our debriefing section and we discuss motivations, strategies, themes, and whether they felt they had been successful during the simulation. Using our observations we discuss the simulation's relevance to politics either in California or in the country as a whole. Students have very astute observations related to the challenges of direct democracy, including the cost of influencing an election, the complex nature of policy solutions versus the simplistic or incomplete nature of propositions, and the lack of accountability in votes. In the following section I describe the most persistent lessons, themes, and behaviors that arise in the simulation.

Leadership within groups. Four different types of leadership emerge during the simulation: group leaders, party whips, treasurers, and dissent. Group leaders will attempt to speak on behalf of their groups during caucusing, bring back negotiated terms to the group, ask clarifying questions to the professor, and explain rules of the simulation to their own party members. Group members often end up overthrowing or replacing their group leader(s) when they are unhappy with negotiated terms or when they feel that their group is losing in the simulation. Often, over time, members of groups begin to question leaders' legitimacy to negotiate and return the necessary votes. Group leaders tend to be more rash, during caucusing, when committing to spending group resources and are reined in by the groups when returning to report to the group.

The party whip emerges as a sub-leader, they often caucus with the group leader, but do most of their work in their own group. They move quickly among their own group members to explain

\footnotetext{
1 Friendships are made and broken during this simulation. Students will bring up perceived slights from the simulation for the
} rest of the semester. 
circumstances, tally preferences and votes. They then report to the leader(s) and often buzz around other groups talking with other groups' party whips. The party whip is almost never replaced during the game and will cooperate with any group leader.

The treasurer keeps track of all the poker chips, hiding them from the other groups and even from the members of their own group. The treasurer does not usually caucus with other groups, rather they remain behind at the group's home base. The treasurer often vetoes the group leader's ideas about negotiation, compromise, and spending of resources. Treasurers tend to be very conservative on spending, especially when it comes to spending in cooperation with another group(s).

The last type of leadership is dissent or opposition leadership within a group. This person acts as the voice of dissent in the group and they do not tend to caucus with other groups. The dissent leader tends to view the leader's actions as too conservative or too reckless, and view them as spending too much or too little. The opposition leader caucuses with the remaining group members and tries to figure out alternative methods for winning the simulation. These dissent leaders are not adverse to the overall goals of the group, they simply disagree with strategy and often miss out on being the first group leader because they didn't move fast enough at the start of the simulation.

Coalitions across groups. Coalitions form as soon as the first proposition is posted. The group leaders quickly ask the other groups about the profile of their group, how the proposition would impact their group, and how they plan to vote. The groups immediately start counting potential votes, group members and group leaders never consider that a member of the group will vote against the interests of the group (and they very rarely do). Groups which form coalitions containing a simple majority of the class no longer seek to convince other groups to join them. They do not wish to negotiate or share any potential costs or gains with additional groups. The minority coalitions form more reluctantly, they know they need each other, but they don't show the same enthusiasm as the majority coalitions. A spokesperson from the minority coalition will usually meet with the majority coalition to try and change their minds, explain why they should change their vote, explain why the cost they (minority groups) will pay will be higher than the benefit of the reward to the majority coalition. During coalition formation coalition partners will try to figure out how many resources their partners have access to. Even amongst coalition partners groups are cagey about sharing resource information.

Given the design of the simulation, coalitions break apart approximately halfway through the simulation. Particular propositions pit former coalition group members against one another. As groups seek out new coalition partners the minority groups, previously excluded, respond with coolness, anger, 
distrust, and demands about resources. As new coalitions form, minority leaders assure their group members that they do not trust their new partners and that the coalitions are temporary.

Secrecy is a hallmark of the simulation. Groups are very secretive about how many resources the group has access to; whether the group is relatively wealthy or resource poor. Groups routinely hide their bags under the tables/desks, sometimes they put the bags inside backpacks, and rearrange their chairs to circle the treasurer. Groups very rarely, and almost never, remove any/all of their chips and/or count or stack them on the table where other groups can view them. When groups come to the professor to trade income for political capital they almost always do so surreptitiously and ignore calls from other groups to explain what they are doing. Groups are also very secretive about deals they arrange with other groups for things like log-rolling or paying the costs to knock candidates or propositions of the ballot. If financial offers are made out loud, group leaders will quickly move to caucus away from other leaders and return to whisper results of their bargaining with group members. Groups are also secretive about their group profiles, trying to keep secret pieces of information that may give away their voting preferences.

Cohesion and Defection. Groups always vote as a bloc. They are not required to do so, groups are able to see that I count individual votes during voting, and group members are allowed to abstain from a vote. However, voting is strictly enforced within groups as they remind group members to hold their cards up high so they can be counted. In the five years running this simulation only one student, one time, voted against his bloc. His own group booed loudly during the vote and asked him to go sit with the other minority groups, where he remained for the rest of the simulation. Group cohesion, even in these minimal groups, is very high and students embrace their new identities. Students take wins and losses very seriously and are outraged when different groups vote down propositions like affordable housing or more affordable higher education.

Apathy and despair from minority group members. In the simulation certain groups have lower starting resources, meaning they have less income and lower political capital. Although these groups may have a chance to earn more resources in the trivia games the initial offset is enough to maintain inequity throughout the simulation. As propositions are introduced these minority groups become increasingly frustrated that they may not have enough votes in their coalition to win a simple majority, and at the same time they may not have enough political capital to influence the votes through spending. What little resources they have, they often hoard, out of fear of what might come next. The times when they do choose to spend, other groups may outspend them, leaving them more resource poor and without 
a win. Toward the middle of the simulation they start commenting "what's the point of us even voting?" and when other groups come to caucus they frequently comment "why are you even here, you don't care what we think." During the halfway point in the simulation when the coalitions break apart and the former majority coalition groups come around looking for new partners minority groups are bitter, apathetic, and distrusting.

Relative gains rule the simulation. Each proposition has a short description of what will happen if the proposition passes or fails. Certain propositions have rewards for all groups in the simulation, but some groups will benefit more than others. The majority coalition groups will routinely vote down or spend to eliminate propositions when they feel another group would gain too much relative to their group. Majority coalitions routinely vote down healthcare reform, affordable housing, and less expensive higher education. This particular lesson is a source of much internal reflection during the debriefing section, as I routinely have a good number of student activists in my classes who gleefully vote down propositions on the very issues they organize for on campus.

The rules! I have a set of rules I use in the simulation, but I take a very hands off approach to running the simulation, I prefer to have students test the boundaries of the simulation to see what is allowed. Some groups figure out new strategies before other groups - this usually causes a bit of chaos and complaints that this is unfair! However, the longer the simulation runs, the more adept all of the students become at navigating our pretend elections(s) system. Groups will often help their coalition partners with the rules, but never the opposition. Groups are also frustrated the legislature and executive cannot do much to amend or stop propositions from passing/failing.

\section{Simulation Modifications}

The simulation can be modified to fit the needs of many different types of courses. Additional propositions can be added, and the propositions themselves can be changed. Changing the propositions necessarily changes the coalitions that form and the negotiations that take place. Propositions can be changed to keep up with current events and the real election cycle. Adding or subtracting propositions can lengthen or shorten the simulation to fit different class periods. The simulation is also easily modified to play without an executive or a legislature, or with expanded powers of the executive or legislature, for example allowing the legislature to take up issues and write legislation. Lastly, the minimal groups in the simulation can be based on any groups in society that you can make a profile for, as an example groups can be based on: voters, residents, probable voters, age demographics, race and ethnicity, regions. 


\section{Conclusion}

The direct democracy simulation has been an important part of my California Politics and Public Policy courses. Students, who are non-majors or majors, are able to engage in active learning as they navigate a simulated election season. During our debriefing and in my end of course evaluations students describe the simulation as one of their favorite and most memorable parts of the class. Students are able to explore the difficulties in creating and maintaining political coalitions. At times groups struggle with their leadership and they frequently replace ineffectual leaders-which can upset balance in the coalition. One of the most contentious parts of the simulation are the inequitable resource allocations, disagreements over resources, and whether to pursue absolute or relative gains. Students wrestle with what is more important-gains for the whole class or gains for their group-they almost always select their own group over the needs of the entire group. Groups in the minority, throughout the simulation, content with apathy and hopelessness. During the debrief they explain a new understanding for the challenges with organizing and mobilizing in communities left out of political representation and political spaces. Related to minority group issues, students also seem to grasp the importance of understanding the political rules, understanding how systems and institutions work can be a major advantage in the simulation. 


\section{Works Cited}

Bloom, B. (Ed.). (1956). The taxonomy of educational objectives, the classification of educational goals, Handbook I: Cognitive domain. New York: McKay.

Brock, Kathy L., and Beverly J. Cameron. "Enlivening political science courses with Kolb's learning preference model." PS: Political Science \& Politics 32, no. 2 (1999): 251-256.

Lantis, Jeffrey S., Kent J. Kille, and Matthew Krain. "The state of the active teaching and learning literature." In Oxford Research Encyclopedia of International Studies. 2010.

Schnurr, Matthew A., Elizabeth M. De Santo, and Amanda D. Green. "What do students learn from a role-play simulation of an international negotiation?." Journal of Geography in Higher Education 38, no. 3 (2014): 401-414.

Silvia, Chris. "The Impact of Simulations on Higher-Level Learning," Journal of Public Affairs Education, 18:2, (2012) 397-422.

Smith, Elizabeth T. and Mark A. Boyer. 1996. “Designing In-Class Simulations.'” PS: Political Science and Politics 29: 690-694.

Tajfel, Henri. "Experiments in intergroup discrimination,” Scientific American. 223 (5): (1970) 96-102.

Tajfel, Henri.; Billig, M. G.; Bundy, R. P. \& Flament, C. (April-June 1971). "Social Categorization and Intergroup Behaviour." European Journal of Social Psychology. 1 (2): (1971) 149-178.

Tajfel, Henri. Tajfel, Henri (ed.). "Interindividual Behaviour and Intergroup Behaviour". Differentiation Between Social Groups: Studies in the Social Psychology of Intergroup Relations: (1978) 27-60.

Wedig, Timothy. "Getting the most from classroom simulations: Strategies for maximizing learning outcomes." PS: Political Science \& Politics 43, no. 3 (2010): 547-555. 
Wheeler, Sarah M. 2006. "Role-Playing Games and Simulations for International Issues Courses.' Journal of Political Science Education 2: 331-347. 